Journal of Current and Advance Medical Research

January 2019, Vol. 6, No. 1, pp. 1

http://www.banglajol.info/index.php/JCAMR

ISSN (Print) 2313-447X

ISSN (Online) 2413-323X

NLM Catalog ID 101673828

DOI: https://doi.org/10.3329/jcamr.v6i1.40772

EDITORIAL

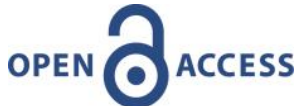

\title{
Role of Radiology in Image Guided Pain Management
}

\author{
Tariqul Islam
}

\begin{abstract}
Assistant Professor, Department of Neuroradiology \& Imaging, National Institute of Neurosciences \& Hospital, Sher-E-Bangla Nagar, Agargaon, Dhaka, Bangladesh; Email: tariqul33@gmail.com; Cell no.: +8801 711192878
\end{abstract}

Pain is often difficult to control which is more appropriate in malignant disease even after using appropriate medications like pain killer wither in oral or injectable form. Image-guided injection is commonly performed in symptomatic patients to decrease pain severity, confirm the pain generator, and delay or avoid surgery. This presentation focuses on the radiologist as interventionist and addresses the topics relevant to the radiologist who performs corticosteroid injections for pain management like the rationale behind corticosteroid injection, the interaction with patients, the role of imaging in procedural selection and planning and the pearls and pitfalls of fluoroscopically or USG or CT-guided injections. Factors that contribute to the success of a pain management service include communication skills and risk mitigation. A critical factor is the correlation of clinical symptoms with magnetic resonance (MR) imaging findings. Radiologists can leverage their training in MR image interpretation to distinguish active pain generators in the spine from incidental abnormalities. Knowledge of fluoroscopic anatomy and patterns of contrast material flow guide the planning and execution of safe and effective needle placement. Anesthesiologists and pain therapists have developed new invasive therapies including nerve block, sympatholysis, and neurolysis useful for both diagnosis and pain management. To insure the efficiency and safety of these procedures, and furthermore for elaborate techniques such as vertebroplasty, cementoplasty, and radio frequency bone ablation, imaging guidance becomes mandatory. This state-of-the-art techniques can be applied by interventional radiologists in the treatment and palliation of a variety of benign and malignant painful conditions.

[Journal of Current and Advance Medical Research 2019;6(1):1]

[Cite this article as: Islam T. Role of Radiology in Image Guided Pain Management. J Curr Adv Med Res 2019;6(1):1] 